\title{
Moderately Abnormal Ejection Fraction
}

National Cancer Institute

\section{Source}

National Cancer Institute. Moderately Abnormal Ejection Fraction. NCI Thesaurus. Code C99508.

Moderately less than normal amount of blood that is forced from the heart ventricle to produce cardiac output. Quantitatively, the ejection fraction is considered between 30\% to $39 \%$. 